Note: This is a pre-copy-editing, author-produced PDF of an article accepted for publication in British Journal of Development Psychology following peer review. The definitive publisherauthenticated version [Morgan M and Grube JW (1989) Adolescent cigarette smoking: a developmental analysis of influences, British Journal of Development Psychology, 7, 179189] is available online at http://bpsoc.publisher.ingentaconnect.com/content/bpsoc/bjdp

\title{
Adolescent cigarette smoking: A developmental analysis of influences
}

\author{
Mark Morgan \\ St Patrick’s College, Dublin 9, Ireland \\ Joel W. Grube \\ Prevention Research Centre, Berkeley, California
}

\begin{abstract}
Published in: British Journal of Development Psychology, 1989, 7, pp.179-189. Copyright: The British Psychological Society
\end{abstract}

\begin{abstract}
This study investigated the influence of various factors associated with smoking behaviour among a randomly selected sample of 3000 Dublin post-primary school pupils. A specific focus was the extent to which these influences change with age during adolescence (13-17 years). Normative influences on smoking behaviour increased up to age 15-16 years and then declined. This curvilinear pattern seems largely due to the rise and decline of peer influences over these years. On the other hand, the influence of parents (both in terms of parental example and approval) is constant over this period. Beliefs about the consequences of smoking were also affected by age. The distinctive contribution of such beliefs to the prediction of smoking doubled during the years under consideration. These results have important implications for the understanding of susceptibility to social influence during adolescence and for the design of effective smoking prevention programmes.
\end{abstract}

Because it is extremely difficult to stop people smoking once they have started (Leventhal \& Cleary, 1980), there has been an upsurge of interest in devising effective intervention strategies to prevent young people from starting to smoke in the first place. Such intervention programmes need to be based on an understanding of the precise influence processes involved in initiation to, and maintenance of, cigarette smoking.

The existing literature indicates that three factors are particularly important in the initiation of smoking and its maintenance. These are (i) normative influences, (ii) beliefs regarding the consequences of smoking and (iii) social bonding factors. Normative influences are defined as an individual's perceptions of social pressures and specifically of the extent to which significant others prescribe or proscribe a particular behaviour (e.g. Ajzen \& Fishbein, 1980). Several studies have shown that young smokers perceive greater social support for smoking and less social pressures against smoking than do non-smokers (Chassin, Presson, Sherman, Corty \& Olshavsky, 1984; Flay, d'Avernas, Best, Kersell \& Ryan, 1983; Grube, McGree \& Morgan, 1984). Two distinct types of norms may be important in determining smoking behaviour: perceived approval and behavioural norms, Perceived approval.consists of beliefs about the approval or disapproval of others for a particular behaviour, while behavioural norms consist of beliefs about the extent to which significant others engage in the behaviour themselves. The recent work of Grube, Morgan \& McGree (1986) has shown that behavioural norms contribute substantially to the prediction of smoking behaviour even after controlling for perceived approval. This outcome suggests that models of normative influences that are limited to perceived approval (e.g. Azjen \& Fishbein, 1980) may underestimate the strength of the normative influences. 
Beliefs about consequences consist of two components: (i) perceptions of the likelihood that a behaviour will have specific personal consequences and (ii) evaluations of these consequences. Several studies suggest that smokers are less likely than non-smokers to believe that their own smoking will bring about negative consequences like lung cancer, offending others and bad breath. They are more likely to believe that it will increase their popularity, make them feel relaxed and help them concentrate (e.g. Bauman \& Chenoweth, 1984; Fishbein, 1982; Grube, McGree \& Morgan, 1984). Similarly, smokers also evaluate the negative consequences of smoking less negatively and the positive consequences more positively than do non-smokers (Fishbein, 1982; Grube et al., 1984).

Social control theory (Hirschi, 1969) suggests that individuals are constrained from engaging in deviant behaviours to the extent that they are socially bonded to conventional institutions like the family, school and the church. The more that social bonding to traditional institutions is weakened, the greater the likelihood that an individual will engage in problem behaviour. There is substantial evidence that social bonding is related to smoking behaviour. For example, young people who report a high degree of attachment to their parents are less likely to smoke (Chassin et al., 1984; Krohn, Massey, Skinner \& Lauer, 1983; Rooney \& Wright, 1982). Similar results have been reported for liking for and attendance at school (Ahlgren, Norem, Hochhauser \& Garvin, 1982; Ensminger, Brown \& Kellam, 1982) and for church attendance and religiosity (Bachman, Johnston \& O'Malley, 1981; Gary \& Berry, 1984).

There are grounds for thinking that there may be developmental changes in the relative strength of these various influences during the acquisition of the smoking habit at adolescence. Et may be that normative influences are more important in the earlier stages of initiation to smoking while nicotine regulation may be more important in the maintenance of smoking (Schachter, 1977). The initial experimentation with cigarettes typically takes place before or during early adolescence and the transition from initial tries to regular smoking takes about two years (Leventhal \& Cleary, 1980). It follows that smoking among older adolescents should be less susceptible to normative influences than in the younger age group, Many developmental studies of conformity to peer pressure point in a similar direction. Peer conformity behaviour increases from childhood to adolescence and then declines in later adolescence (Berndt, 1979; Costanzo \& Shaw, 1966; Iscoe, Williams \& Harvey, 1963).

Three studies have examined developmental changes in the factors associated with smoking. Mangan \& Golding (1983) analysed the association of various factors (aspects of motivation, mood control, stimulation seeking, as well as indicators of psychological disturbance) with recruitment to smoking. The correlates of smoking were dependent on age and gender, although there was no clear developmental pattern. Krosnick \& Judd (1982) investigated peer and parent influences in relation to smoking among 11- and 14-year-olds and they found that parent influence did not differ at the two age levels while peer influence tended to be stronger for the older age group. On the other hand, Chassin, Presson, Sherman, Montello \& McGrew (1986) found that the magnitude of parent and peer influences did not vary significantly across the sixth to the 11th grade.

This study examined the pattern of influences associated with smoking from age 13 to 17 years. Two levels of generality were considered, i.e. domains of influence and specific predictors within these domains. Three domains of influence - normative influences, beliefs about consequences and social bonding - were considered in relation to (i) the overall association of each domain with current smoking behaviour at each age level and (ii) the distinctive contribution of each domain (i.e. the extent to which each domain of influence is associated with smoking while controlling for other domains). Specific predictors within each domain of influence were also analysed to see the extent to which associations of specific influences with smoking might change over these same years. 


\section{Method}

\section{Surrey design}

This report is based on a panel survey, in which the same sample of Dublin post-primary pupils anonymously completed questionnaires in February 1984 and again in March/April 1984. The questionnaires asked about a range of variables relating to cigarette smoking, particularly frequency of smoking behaviour during the previous month, normative beliefs, beliefs about consequences, social bonding and background characteristics. Questionnaires were matched across the two phases by means of a self-generated code (Grube, Morgan \& Kearney, in press; Kearney, Hopkins, Mauss \& Weisheit, 1984). The subsequent analyses, however, are cross-sectional in nature because the one-month interval was too short to examine changes in smoking status.

\section{Sample}

The target area for the study was the greater Dublin area and the sample frame was the official Department of Education list of post-primary schools. The sampling unit consisted of classes within schools. Thus, for each post-primary class level a sample of schools was obtained, stratified for gender, size and type of school (secondary, comprehensive/community or vocational). All but two of the 24 selected schools agreed to participate. These two schools were replaced from the original sampling list by other schools matched on the selection characteristics. At phase 1, 2927 pupils were present on the day of testing and completed the survey. At phase 2, data were obtained from 2782 students. An examination of the characteristics of the students showed that they were representative of the Dublin postprimary school population in terms of gender, age and social background.

\section{Survey instruments}

The survey instruments consisted of self-administered, structured questionnaires. For the most part, the format was relatively simple, with the respondents being asked to circle the appropriate answer or number for each question. Written instructions within each questionnaire assured the respondents of complete anonymity and confidentiality. Respondents were asked if they had ever smoked a cigarette and, if so, at what age they had first smoked and how many cigarettes, on average, they had smoked daily during the past month using an eight-point scale ranging from 'none' to '> 20 cigarettes a day'. Pupils were also asked to indicate how many cigarettes they believed their father, mother, best friend and other good friends smoked each day, and the extent to which these others would approve or disapprove if the respondent were to smoke. Beliefs regarding the consequences of cigarette smoking were measured by asking the students to indicate how likely they thought it was that each of 14 consequences would happen to them personally if they were to smoke (certain it would - certain it would not) and then to evaluate each of these consequences (very goodvery bad).

A further set of questions was concerned with bonding to religion, school family and peers. The pupils were asked to indicate on five-point scales how often they prayed on their own and how important religion was to them personally. In a similar fashion, they were asked him well they thought they did in school relative to other students, and how important they felt it was to do well in school; how well they got along with their parents and friends; and how important they thought it was to get along with these people.

Questions relating to background factors concerned date of birth, gender, and mother's and father's occupations. These occupations were coded into one of eight occupational status categories using an adaptation of the Hall-Jones' scale (McGreil, 1977). Finally, three items were included solely as part of a self-generated identification code that was used to link each student's questionnaires over the phases: number of older brothers, number of older sisters and first letter of mother's Christian name. Items on background factors and the self- 
generated identification code were repeated in identical format at phase 2 as was the question on frequency of previous month's smoking.

Surrey administration

The survey materials were completed in the students' regular classroom setting in all but one school. The exception was a school that required the pupils to complete the questionnaire as a group. In all cases the surveys were administered by trained and experienced interviewers from the Economic and Social Research Institute. In general, the teachers were not present during the testing sessions. However, in a few instances where disciplinary problems were anticipated, the class teacher was present but participated" minimally in the procedures.

\section{Matching procedure}

The matching of questionnaires across phases was accomplished by means of a self-generated code and an off-one marching procedure (Grube et al., in press; Kearney et at., 1984). There were seven elements to this code: gender, day, month and year of birth, number of older brothers, number of older sisters and first initial of mother's Christian name. These elements were used to link the questionnaires from phase 1 with those from phase 2 within each school and class level.

After eliminating eight cases with duplicate codes and 36 cases with missing data on two or more code elements, 1677 pairs of questionnaires with perfect matches on all seven elements were obtained. A second search was then undertaken which allowed questionnaires to be matched if they were identical in all code elements but one. This procedure has been shown to increase the rate of matching significantly while adding a negligible number of erroneous matches (Kearney et al., 1984). Allowing the codes to differ by one element led to an additional 399 matched questionnaires after eliminating duplicate matches. Therefore a total of 20" 6 matched sets of questionnaires from phase 1 and phase 2 was obtained. This number represents about 75 per cent of the maximum number of possible matches. Given a usual absence rate of about 10-15 per cent, the self-generated code appears to be quite successful. ${ }^{1}$

\section{Results}

Reliability of smoking measures

The level of consistency between reported lifetime smoking and current smoking was high. The percentage of respondents who said that they had never smoked, but then indicated that they had, in fact, smoked within the past month, was less than 0.3 per cent. The test-retest reliability was also quite satisfactory. For previous month's smoking, $\mathrm{r}-0.83$ for the total sample while for the exact matches and off-one matches, $r=0.84$ and 0.81 , respectively.

\section{Reliability oF belie and social Bonding measures}

To investigate the multidimensionality of these measures, all the relevant items were subjected to a principal components analysis, with an oblique rotation $($ delta $=0)$. The results of the factor analyses are reported in Grube \& Morgan (1986) and are not shown here. These analyses indicated that the measures showed good convergent and discriminant validity, with the number and nature of the factors corresponding to the relevant dimension of belief and social bonding. Moreover, for the most part the items loaded on a single factor as expected.

\footnotetext{
${ }^{1}$ Just over two-thirds of the sample had smoked at some time in their lives. The percentages were 51.9, 64.8, 70.0, 73.2 and 73.6 for the 13-, 14-, 15-, 16- and 17-year-olds, respectively. The corresponding percentages for current smoking (i.e. during the previous munch) were 26.9, 36.8, 38.9, 42.7 and 39.0 for the same age groups
} 
Only three items were discarded on the grounds that they loaded less than 0.40 " on a relevant factor and/or loaded on more than one factor.

The internal reliability of coefficients (alphas) ranged from 0.35 for school bonding to 0.83 for parental approval of smoking. The median reliability coefficient was 0.74 . For the most part the reliabilities appear to be satisfactory. However, in the case of bonding to school, the level of reliability of the two items is quite unsatisfactory, and the results for this scale should be treated with caution.

\section{Socio-demographic Factors and current smoking}

An initial analysis examined the extent to which age, gender, father's occupational status and maternal employment (working outside the home vs. working exclusively in the home) were associated with current smoking. The dependent measure for these analyses was the mean number of cigarettes smoked daily, averaged across the two phases of the study. The rationale for using this mean is that it provides a more stable estimate of the smoking behaviour of students than one phase alone.

As can be seen in Table 1, the socio-demographic variables as a whole account for only 4 per cent of the variance in current smoking behaviour. Furthermore, only age shows a significant association with smoking, with older adolescents tending to smoke more. On the other hand neither the effects of gender or social class (as measured by father's occupational status) nor of maternal employment reached significance.

Commonality analysis of domains of predictors

A central question concerns the overall magnitude of the relationships of the various domains of influence with smoking. Another important issue is the extent to which any of these domains contributes uniquely to prediction of smoking behaviour. Table 2 shows the results of the commonality analysis designed to answer these questions among each age group from 13 to 17 years. Commonality analysis is a method of variance partitioning that identifies the proportion of variance that may be attributed uniquely to a predictor variable (Pedhazur, 1982). The unique contribution of a predictor variable is defined as the variance attributable to it when entered last in the regression equation, i.e. when other domains of influence are controlled.

Table 1. Socio-demographic factors and current smoking

\begin{tabular}{lccc}
\hline Variable & Standard error & beta & $\mathrm{t}$ \\
\hline Gender & 0.059 & 0.039 & 1,97 \\
Age & 0.020 & 0.193 & $9.89^{*}$ \\
Father's occupational status & 0.013 & 0.009 & 0.48 \\
Maternal employment & 0.062 & 0.024 & 1.23 \\
\hline
\end{tabular}

$\mathrm{R}^{2}=0.04, \mathrm{~F}=27.91$, d.f. $=4,2590, \mathrm{P}<0.001$

A first noteworthy point about Table 2 is that the overall predictability of smoking (deriving from all domains in combination) shows a curvilinear relationship with age. Thus the total variance accounted for increases from 42 per cent at age 13 to a peak of 64 per cent at age .15 and declines to 58 per cent at age 17 . 
Table 2. Total association and unique contribution of each category of predictors at each age

\begin{tabular}{lcccccccccc}
\hline & \multicolumn{4}{c}{ Total association } & \multicolumn{5}{c}{$\begin{array}{c}\text { Unique contribution } \\
\text { Age group }\end{array}$} \\
\cline { 2 - 12 } \multicolumn{1}{c}{ Domain } & 13 & 14 & 15 & 16 & 17 & 13 & 14 & 15 & 16 & 17 \\
\hline Normative factors & 0.26 & 0.37 & 0.45 & 0.45 & 0.38 & 0.12 & 0.16 & 0.16 & 0.15 & 0.09 \\
Beliefs about & & & & & & & & & & \\
$\quad$ consequences & 0.23 & 0.27 & 0.30 & 0.30 & 0.32 & 0.08 & 0.13 & 0.16 & 0.16 & 0.18 \\
Social bonding & 0.13 & 0.11 & 0.13 & 0.15 & 0.12 & 0.04 & 0.01 & 0.01 & 0.01 & 0.01 \\
All predictors & 0.42 & 0.53 & 0.64 & 0.62 & 0.58 & & & & & \\
\hline
\end{tabular}

Note. Total association is the squared multiple correlation of a category of predictors with smoking behaviour. The unique contribution of a set is the $\mathrm{R}^{2}$ increment when that set is added to the regression equation after all other categories of predictors have been entered.

Furthermore, the amount of variance that can be uniquely attributed to specific domains is about half of the total variance accounted for at any given age. The unique contribution of normative influences increases up to age 14 and remains at this level up to age 16 when it drops substantially. On the other hand, the distinctive contribution of beliefs about consequences increases consistently over the years. This is all the more noteworthy in view of the fact that the overall predictability of smoking from the targeted variables decreases from age 15 onwards. It is particularly striking that at age 13 normative influences uniquely account for 12 per cent of the variance while the corresponding figure for beliefs about consequences is 8 per cent. By age 17, however, the unique contribution of normative influences has fallen to 9 per cent while that of beliefs about consequences is double this. Finally, the commonality analysis suggests that social bonding factors account uniquely for 4 per cent of the variance at age 14 and drop to a level of 1 per cent thereafter.

Predictors of smoking across age groups

The analysis' described above was concerned with broad domains of influence. The relationship between the specific predictors within each domain and smoking behaviour was also examined over the various age levels. For example, within the normative domain the pattern of change over the years in the influence of perceived approval and behavioural norms (of peers and parents) was tested in accordance with the procedures suggested by Pedhazur (1982). The critical question was whether using separate regression equations for each age group would add significantly to the proportion of variance accounted for compared with that obtained when a common regression coefficient is used. To carry out this test a set of product vectors (age $\mathrm{x}$ target variable) was generated to represent the interactions. The test of significance was carried out by testing the increment in the proportion of variance resulting from the addition of the product vectors to the regression equation. For this analysis the scores were centred around the mean, i.e. in standard deviation form.

Table 3 shows the (zero-order) correlation of each predictor. Also shown is the trend in the magnitude of the correlation from age 13 to age 17 years. This table also shows the results of the tests for the significance of each age $\mathrm{x}$ predictor interaction, carried out in accordance with the procedures described above.

Considering first the normative influences, it can be seen that the relative influence of approval vs. example is dependent on the reference group under consideration. Thus in the case of peers, it seems that peer smoking is a far stronger predictor than is peer approval. Conversely, perception of level of parental disapproval relates significantly to smoking while parental smoking does not. No interaction with age was apparent in the case of parental influences, while significant curvilinear interactions were evident for peer smoking and peer approval. The relationship of both kinds of peer influence increases up to about age 15-16 years and declines thereafter. 
Overall relationships between beliefs about consequences and smoking are much stronger in the case of perceptions of the likelihood of negative consequences, and in the evaluation of these consequences, than in relation to positive consequences. However, significant interactions with age were evident for three of the four components of expectancy-value beliefs. Over the years the perception of negative consequences (likelihood and evaluation) increased in importance while on the other hand the perception of positive consequences declined in importance (likelihood) or remained stable (evaluation).

Table 3. Interactions of age and influences

\begin{tabular}{lclc}
\hline Influence & r & $\begin{array}{c}\text { Trend over age } \\
\text { groups }\end{array}$ & $\begin{array}{c}\text { Influence x age } \\
\text { interaction F }\end{array}$ \\
\hline Parental smoking & $0.083^{*}$ & Stable & 3.02 \\
Peer smoking & $0.613^{*}$ & Curvilinear & $24.90^{*}$ \\
Parental approval & $0.349^{*}$ & Stable & 6.88 \\
Peer approval & $0.294^{*}$ & Curvilinear & $36.18^{*}$ \\
Likelihood of positive consequences & 0.044 & Decrease & $24.69^{*}$ \\
Likelihood of negative consequences & $0.340^{*}$ & Increase & $19.14^{*}$ \\
Evaluation of positive consequences & $0.054^{*}$ & Stable & 3.57 \\
Evaluation of negative consequences & $0.338^{*}$ & Increase & $27.39^{*}$ \\
Bonding to school & $0.261^{*}$ & Stable & 5.09 \\
Bonding to religion & $0.249^{*}$ & Stable & 4.60 \\
Bonding to family & $0.232^{*}$ & Stable & 2.91 \\
Bonding to peers & 0.031 & Stable & 0.30 \\
\hline
\end{tabular}

$* \mathrm{P}<0.001$.

Three of the four social bonding items relate significantly to smoking. These three domains (school, religion and family) relate equally strongly to the dependent variable. In contrast, bonding to peers was unrelated to this behaviour. Furthermore, there was no indication of an age $\mathrm{x}$ bonding interaction for any domain.

\section{Discussion}

The results go some way towards clarifying the nature of the influences on smoking behaviour. The relative influence of behaviour vs. approval depended on the reference group being considered within the normative domain. In the case of behavioural example the peer group carried most influence. However, parental attitudes carried the greatest weight when it came to approval. Peer group example has a profound impact on smoking, while peer group approval is relatively less important. Conversely, the pattern of influences of parents is largely mediated through their perceived approval, while the example of parents seems to be a relatively unimportant factor.

Studies that have compared the impact of parents vs. peers in relation to cigarette smoking (e.g. Krosnick \& Judd, 1982), but have not considered both approval and behaviour, may not be giving a complete picture of the interacting influences. In particular, the several studies that have shown a weak or insignificant relationship between parent and child smoking (Brook, Whiteman, Gordon \& Brook, 1984; McAlister, Krosnick \& Milburn, 1984) may have led to an underestimate of parental influence as regards smoking. Interestingly, the work of Biddle, Bank \& Marlin (1980) and of Bank, Biddle, Anderson, Hauge, Keats, Keats, Marlin \& Valantin (1985) provides strong support for the distinctions advocated here in the context of studies of adolescent drinking in five countries. While Bank et al. found differing patterns of influences in these various countries, the relative impact of parents and peers was found to 
depend on whether drinking behaviour or approval of drinking was considered, i.e. behavioural norms or perceived approval as in this study.

Bonding to parents, school and religion emerged as significant but weak predictors of smoking behaviour. However, these factors collectively made a lesser 'unique' contribution to the prediction of smoking than either normative influences or beliefs about consequences. The finding that peer bonding was unrelated to smoking is especially interesting since the original Hirschi (1969) study found that bonding to peers was related negatively to delinquency.

The relationship of the normative domain with smoking is curvilinear both in terms of absolute association and in terms of the distinctive contribution to prediction. The commonality analysis shows that the association increases up to age 16 years and then declines. This outcome is precisely what was predicted on the basis of studies relating age to susceptibility to conformity (e.g. Berndt, 1979).

An examination of the relationship of the specific predictors (within the domain of normative influences) with smoking behaviour sheds further light on the nature of this interaction and supports the view that the pattern over the years reflects the changing susceptibility to peer rather than parental influences. Both peer behaviour and peer approval show similar patterns, increasing in importance up to age 15-16 years and then decreasing, while parental influences remain remarkably stable.

In addition, the commonality analysis shows that beliefs about consequences become increasingly important during adolescence. While the total association of this domain with smoking behaviour increases modestly but consistently, the unique contribution more than doubles in size. Interestingly, this pattern seems due to the increasing differences between smokers and non-smokers in relation to the perception of the negative consequences of smoking (harming health, costing money, bad breath, etc.). It seems that increasing age during the adolescent years was associated with a greater tendency for smokers to perceive these consequences as being less likely to occur to them and also with a greater tendency to rate these same consequences as being unimportant.

The results are in agreement with those of Krosnick \& Judd (1982) who found that peer influence was relatively greater among 14-year-olds than among 11-year-olds. The Krosnick \& Judd study examined peer smoking only while the present study found a similar pattern for peer approval. It is also interesting to note that parental influences (both smoking and approval) were similar at both age levels in the Krosnick \& Judd study, an outcome which is replicated here.

In contrast, the findings of Chassin et al. (1986) seem to suggest that the magnitude of parent and peer influences do not differ significantly between 12- and 17-year-olds. However Chassin et al. focused on changes in smoking status at different age levels, i.e. initiation to smoking and transition from experimenter to regular smoker. In contrast, our study was directed towards the issue of age-related differences in the predictors of smoking frequency, regardless of stage. While it is true that the present results may be due to either maturation effects (Berndt, 1979; Krosnick \& Judd, 1982) or to differences in stage of smoking that are coincidentally related to age, the point remains that different processes and intervention strategies are indicated for different age groups.

The issue of developmental changes in influences on smoking has important implications for intervention strategies. While there are various types of smoking prevention programmes, a useful distinction can be made between those that provide information of consequences and those that concentrate on resistance to social pressure. The latter approach has been considered to be relatively more successful (Grube \& Morgan, 1986). However, Leventhal \& Cleary (1980) criticize such programmes for failing to take into account the developmental stages of smoking and the assumed developmental changes of mediating factors. They argue that the almost exclusive focus on resisting peer pressure may be unnecessarily limiting and may be relevant only to initiation to smoking. 
Our results support the Leventhal \& Cleary criticism. While teaching resistance to peer pressure may be effective in early adolescence, the usefulness of such techniques may be smaller in late adolescence. In addition, an emphasis on the likelihood of particular negative consequences occurring, as well as stress on the importance of such consequences, is likely to be effective in programmes aimed at older adolescents and at young adults.

\section{Acknowledgements}

This research was funded in part by a grant from the Commission of the European Communities and supported by the Educational Research Centre, St Patrick's College, and by the Economic and Social Research Institute.

Thanks are due Michael Martin for his statistical advice.

\section{References}

Ahlgren, A., Norem, A. A., Hochhauser, M. \& Garvin, J. (1982). Antecedents of smoking among pre-adolescents. Journal of Drug Education, 12, 325-340.

Ajzen, I. \& Fishbein, M. (1980). Understanding Attitudes and Predicting Social Behavior. Englewood Cliffs, NJ: Prentice-Hall.

Bachman, J. G., Johnston, L. D. \& O'Malley, P. M. (1981). Smoking, drinking and drug use among American high school students: Correlates and trends. American Journal of Public Health, 71, 59-69.

Bank, B., Biddle, B. J., Anderson. D. S., Hauge, R., Keats, D. M., Keats, J. A., Marlin, M. M. \& Valantin, S. (1985). Comparative research on the social determinants of adolescent drinking. Social Psychology Quarterly, 48, 164-177.

Bauman, K. E. \& Chenoweth, R. L. (1984). The relationship between the consequences adolescents expect from smoking and their behaviour: A factor analysis with panel data, Journal of Applied Social Psychology, 14, 28-41.

Berndt, T. J. (1979). Developmental changes in conformity to peers and parents. Developmental Psychology, 15, 606-616.

Biddle, B. J., Bank, B. J. \& Marlin, M. M. (1980). Social determinants of adolescent drinking: What they think, what they do and what I think and do. Journal of Studies on Alcohol, 41, 215-241.

Brook, J. S., Whiteman, M., Gordon, A. S. \& Brook, D. W. (1984). Identification with paternal attributes and its relationship to the son's personality and drug use. Developmental Psychology, 20, 1111-1119.

Chassin, L., Presson. C. C., Sherman, S. J., Corty, E. \& Olshavsky, R. W. (1984). Predicting the onset of cigarette smoking in adolescents: A longitudinal study. Journal of Applied Social Psychology, 14, 224-243.

Chassin, L., Presson, C. C., Sherman, S. J., Montello. D. \& McGrew. J. (1986). Changes in peer and parent influence during adolescence: Longitudinal versus cross-sectional perspectives on smoking initiation. Developmental Psychology, 22. 327-334.

Contanzo, P. R \& Shaw. M. E. (1966). Conformity as a function of age level. Child Development, 37, 967-975.

EnsmingermM. E., Brown, C. H. \& Kellam, S. G. (1982). Sex differences in antecedents of substance use among .adolescents. Journal of Social Issues, 38, 25-42.

Fishbein, M. (1982). Social psychological analysis of smoking behavior. In R. E. Eiser (Ed.), Social Psychology and Behavioral Medicine, pp. P9-197. New York: Wiley.

Flay, B. R., d'Avernas, J. J., Best, J. A., Kersell, M. W. \& Ryan, K. B. (1983). Cigarette smoking: Why young people do it and ways of preventing it. In P, J. McGrath \& P, Firestone (Eds), Pediatric and Adolescent Behavioral Medicine: Issues in Treatment. New York: Springer. 
Gary, L. E. \& Berry, G. L. (1984). Some determinants of attitudes toward substance use in an urban ethnic community. Psychological Reports, 54, 539-545.

Grube, J. W., McGrce. S. \& Morgan, M. (1984). Smoking behaviours, intentions and beliefs among Dublin primary school children. The Economic and Social Review, 15, 265288.

Grube, J. W., \& Morgan, M. (1986). Smoking, Drinking and Other Drug Use among Dublin Post-primary School Pupils. Dublin: Economic and Social Research Institute.

Grube, J. W., Morgan, M. \& Kearney, K. A. (in press). Using self-generated identification codes to match questionnaires in panel studies of adolescent substance use. Addictive Behaviors.

Grube, J. W., Morgan, M. \& McGrce, S. (1986). Attitudes and normative beliefs as predictors of smoking intentions and behaviours: A test of three models. British Journal of Social Psychology, 25, 81-93.

Hirschi, T. (1969). The Causes of Delinquency, Berkeley, CA: University of California Press.

Iscoe, I., Williams, M. \& Harvey, J. (1963), Modifications of children's judgements by a simulated group technique: A normative developmental study. Child Development, 34, 963-978.

Kearney, K. A., Hopkins, R. H., Mauss, A. L. \& Weisheit, R. A. (1984). Self-generated identification codes for anonymous collection of longitudinal questionnaire data. Public Opinion Quarterly, 48, 370-378.

Krohn, M. D., Massey, J. L., Skinner, W. F. \& Lauer, R. M. (1983). Social bonding theory and adolescent cigarette smoking: A longitudinal analysis, Journal of Health and Social Behaviour, 24, 337-349.

Krosnick, J. A. \& Judd, C. M. (1982). Transitions in social influence at adolescence: Who induces smoking? Developmental Psychology, 18, 359-368.

Leventhal, H. \& Cleary, P. D. (1980). The smoking problem: A review of the research and theory in behavioral risk modification. Psychological Bulletin, 88, 370-405.

McAlister, A. L., Krosnick, J. A. \& Milburn, M. A. (1984). Causes of adolescent smoking: Tests of a structural equation model. Social Psychology Quarterly, 47, 24-36.

McGreil, M. (1977). Prejudice and Tolerance in Ireland. Dublin: College of Industrial Relations.

Mangan, G. L. \& Golding, G. F. (1983). Factors underlying smoking recruitment and maintenance amongst adolescents. Advances in Behaviour Research and Therapy, 4, 225-272.

Pedhazur, E. (1982). Multiple Regression in Behavioral Research. New York: Holt, Rinehart \& Winston. Rooney, J. F. \& Wright, T. L. (1982). An extension of Jessor and Jessor's problem behaviour theory from marijuana to cigarette use. The International Journal of the Addictions, 17, 1273-1287.

Schachter, S. I. (1977). Nicotine regulation in light and heavy smokers. Journal of Experimental Psychology; General, 106, 5-12. 